\title{
Beyond Improved Access: Seasonal and Multidimensional Water Security in Urban Philippines
}

\author{
Lisa Reyes Mason
}

Published online: 15 November 2014

(C) Springer International Publishing 2014

\begin{abstract}
Purpose Water is a basic human right that is still not ensured for many people worldwide. Essential for human health and development, water security is an increasingly important area for social welfare research. At the household level, a common water security proxy is access to an improved source of drinking water such as piped water, a public tap, or a protected well. In urban areas of developing countries, however, recent research has identified important household disparities that regional and national statistics on improved access can mask. To extend these analyses, this study examines seasonal differences in household water security - an emerging priority area due to urbanization, population growth, and environmental change trends.

Methods Data are from randomly sampled household surveys $(N=396)$ in Baguio City, the Philippines, on water quantity, quality, and accessibility in dry versus rainy seasons. Bivariate and principal component analyses were performed.

Results Water quantity and accessibility are lower in the dry than rainy season for several measures, typically with a wide range among households. Water quality is rated somewhat higher in the dry than rainy season. Principal component analysis yields a multidimensional measure of dry season hardship and no comparable rainy season measure.

Conclusions Important heterogeneities of seasonal water security exist among households in this study. More rigorous documentation of local inequities is needed, incorporating seasonal aspects of water security that are appropriate for local contexts.
\end{abstract}

L. R. Mason $(\bowtie)$

College of Social Work, University of Tennessee, 321 Henson Hall, 1618 Cumberland Avenue, Knoxville, TN 37996, USA

e-mail:1mason12@utk.edu
Keywords Water · Urbanization · Environmental change · Seasonality $\cdot$ Household disparities $\cdot$ Philippines

\section{Introduction}

Water is a basic human right, essential for human health, development, and the realization of other rights (UNICEF and World Health Organization 2012). At the nexus of social, economic, and environmental concerns, ensuring water security for vulnerable and marginalized groups is an important and emerging area for social welfare research (Pawar 2013; Schmitz et al. 2012). Analogous to the concept of food security, water security can be conceived from a basic needs perspective as access "by all people, at all times, to adequate water for an active and healthy lifestyle" (Wutich and Ragsdale 2008, p. 2117). ${ }^{1}$

At the household level, a common proxy for water security is access to an improved source of drinking water, where an improved source is considered piped water into a dwelling or yard, a public tap or standpipe, a protected well or borehole, a protected spring, or rainwater. In 2010, the Millennium Development Goal of halving the proportion of the world's population without improved access was achieved 5 years ahead of schedule, with important implications for child morbidity and mortality, women's well-being, and household economic outcomes (Cheng et al. 2012; Pickering and Davis 2012; UNICEF and World Health Organization 2012; United Nations Development Programme 2006).

The limitations of improved access as a proxy, however, are well known. Water from improved sources may be inadequately supplied, unclean, hard to obtain, or prohibitively

\footnotetext{
${ }^{1}$ For non-basic needs conceptualizations of water security, including perspectives which include ecological and governance dimensions, see Jepson (2014) and Pawar (2013).
} 
expensive. Yet, standard measures of household water security in lieu of this proxy do not exist (Jepson 2014). At minimum, the concept of water security from a basic needs lens includes dimensions of water quantity, quality, and accessibility, each of which has the potential to be distinctly measured (Gleick 1998; Howard and Bartram 2003; Satterthwaite 2003).

Recently, the World Health Organization and UNICEF Joint Monitoring Programme called for new attention to multidimensional approaches to understanding water disparities - for all everyday household needs including drinking, cooking, hygiene, and cleaning (UNICEF and World Health Organization 2012). These approaches can be especially productive at local and community levels, as regional and national statistics on improved access can mask disparities in water security that exist among a population (Bradley and Bartram 2013; Satterthwaite 2003). In urban areas, recent community-based research on water security has started to identify such disparities among households (Carolini 2012; Jepson 2014; Mason 2012; Romero 2010; Subbaraman et al. 2013; Wutich and Ragsdale 2008). To extend these analyses, this study focuses on seasonality of household water security in urban Philippines with a multidimensional approach that examines quantity, quality, and accessibility of water for everyday use.

Notably, very few studies have examined such seasonality in urban communities to date (Mason 2012; Subbaraman et al. 2013; Wutich and Ragsdale 2008). Yet, seasonality is an emerging priority area for understanding water disparities due to convergent trends of urbanization, population growth, and global environmental change (McDonald et al. 2011; Muller 2007; Schneider et al. 2007; UNICEF and World Health Organization 2012). During dry seasons, for example, water supplies may decrease or become prohibitively expensive; during rainy seasons, rainfall may provide an additional water source, but water quality from some sources may be poor (Hamdan 2009; Vairavamoorthy et al. 2008).

This study provides one of the first systematic documentations of multiple dimensions of water security in an urban community-Pinget in Baguio City, the Philippines-with distinct seasonal change. In addition, by using both objective and subjective measures of water security, this study contributes to the growing literature on the importance of including subjective measures when assessing basic needs and well-being (Guardiola and García-Muñoz 2011; Jepson 2014). Finally, the study provides an empirical contribution to emerging social welfare scholarship on social and environmental problems such as the impact of global environmental change on vulnerable and marginalized groups (Dominelli 2013; Kemp 2011). Findings can inform both local efforts to target water policies and programs, and broader discussions of how to measure water security progress beyond the Millennium Development Goals-from improved access toward universal access for everyday household needs.

\section{Water in Urban Philippines}

The Philippines was selected for this study due to its demographic, environmental, and water source characteristics, particularly in urban areas such as Baguio City where this study took place. Like many countries worldwide, the Philippines is rapidly urbanizing, which can strain the delivery of public goods and services. Today, almost $50 \%$ of its population is urban, and by 2050 , the country is expected to have the 10th largest urban population worldwide (United Nations Population Division 2010). Also, as in many countries, global environmental change, including climate change specifically, and its consequences for human well-being are of growing concern to Filipino policymakers and the general public (Pajuelas 2000; Philippines Institute for Development Studies 2009). Although a direct link with climate change cannot be assumed, since 2004, the Philippines has experienced several years of either prolonged dry periods and drought, or extreme rainfall and heavy typhoon activity (Yumul et al. 2011) with possible implications for water security in this context.

Nationally, an estimated $92 \%$ of Filipinos are reported as having access to an improved source of water (UNICEF and World Health Organization 2012). As described above and as recently documented by Fehr et al. (2013) for different regions of the Philippines, this measure likely overestimates water security in comparison to alternative and more comprehensive measures that could be used. Further, this estimate does not consider seasonality of improved access, which is important due to the geographic location, topography, and climate variability of the country (Yumul et al. 2011). Given climate trends and projected climate scenarios-which call for possible extended dry seasons and heavier rainy seasons in many areas, including Baguio City where this study took place (Rybski et al. 2014) - connections between seasonality and water security are increasingly important to understand and may inform local policy, as well as policy in other contexts where similar changes are expected to occur.

Situated in northern Philippines, Baguio City has a population of 300,000. The city has a dry season from November to April (mean monthly precipitation, $50 \mathrm{~mm}$ ) and a rainy season from May to October (mean monthly precipitation, $590 \mathrm{~mm}$ ). Many households throughout the city receive piped water from the Baguio Water District (BWD), the quasigovernmental local water utility, although BWD is unable to provide the exact number of households served. Due to Baguio City's mountainous topography and limited access to surface water, BWD relies primarily on electrically powered 
deep wells to produce an estimated $50,000 \mathrm{~m}^{3}$ of water per day, with $40 \%$ system loss due primarily to aging infrastructure (Baguio Water 2011).

Although piped water from BWD is considered an improved source, not all households are connected to the utility, distribution is intermittent and rationed year round (e.g., water may be provided 3 days per week for $4 \mathrm{~h}$ per day), and quality at point-of-use is suspect among many consumers since contaminants can enter aging distribution pipes when supply is intermittently turned off (Asian Development 2006). Many households thus rely on portfolios of water sources to meet their everyday water needs (Mason 2012), relying to different extents on water from one or more of the following: their own BWD connection, others' BWD connection (e.g., paying a relative or landlord for BWD water), private delivery companies (e.g., businesses that sell water via tanker truck), purified water vendors, protected and unprotected springs, rainwater, domestically recycled water, and community deep wells. Not surprisingly, basic supply of water from different sources can vary seasonally, for example, as rainy seasons help recharge underground aquifers and may provide needed reserves of water for dry seasons.

\section{Methods}

This study is part of a larger research project on water security that took place in Baguio City from November 2011 to April 2012. The study was institutionally reviewed and approved for ethical conduct of research, and informed consent was obtained from all participants before data collection began. The research team consisted of myself and eight multilingual research assistants who were hired locally and who completed training in ethical human subjects research.

\section{Study Neighborhood}

In Baguio City, neighborhood-level access to BWD and other water sources can vary widely (Mason 2012). Hence, I sought a particular neighborhood for this study that would capture some of this Baguio-wide variability within its own boundaries. After conducting archival research at the Baguio City Planning Office, interviews with agency officials, and meetings in prospective neighborhoods, I selected Pinget as the study neighborhood. Pinget is one of the most populated and densely settled areas in Baguio City, with a socially and economically diverse population of about 8000 people. Although conducting the study in one neighborhood hindered generalizability to greater Baguio City, this approach allowed me to conduct rigorous random sampling in the selected neighborhood while collecting household data on each kind of water source available in the greater area.

\section{Survey Sample}

As part of the larger research project, our team conducted 396 randomly sampled household surveys, administered in person in the respondent's preferred language (e.g., Ilocano, Tagalog, etc.). We constructed the sampling frame by updating the 2009 neighborhood census list with information gathered by canvassing the neighborhood to add newly built or overlooked housing units to the list and to exclude vacant units, for a total of 1793 cases. I then stratified the frame by purok (neighborhood subdistrict) and permanent or boarder (renter) status, and randomly selected $25 \%$ from each stratum for a total of 454 cases. Of these, 38 or $8.4 \%$ were determined ineligible (vacant or duplicate units). Among eligible cases, 95.2\% agreed to participate for a final sample of 396 households. Recruitment occurred in person, as research team members went door-to-door among households selected for the study. A small study incentive of dry goods (e.g., coffee, powdered milk) was provided.

The survey respondent was the household water manager, at least 18 years of age, defined as the person most responsible for ensuring the household has the water that it needs for everyday use. Among respondents, $79.8 \%$ were female, $74.9 \%$ had at least a high school diploma, and $69.3 \%$ were married or had a domestic partner. Average respondent age was 39.7 years, with a range of 18 to 90 . Average length of residency in Pinget was 15.3 years, with a range of 1 month to 52 years.

Household demographics in Pinget (Table 1) reflect the social and economic diversity that is characteristic of many Baguio City neighborhoods. Monthly income varies widely with a dry season range of 718 (\$16.77) to 77,000 (\$1799.07) and a similar rainy season range. In Pinget—like greater Baguio City - most households store water in one or more 200-L drums or large-volume tanks as an adaptation to intermittent water supply. Average household storage capacity is $1934.1 \mathrm{~L}$, with a range of 0 to $12,800 \mathrm{~L}$ and a high standard deviation. Finally, $43.2 \%$ of households report having their own piped BWD connection, $31.1 \%$ access BWD water in some other way (e.g., paying a landlord, relative, or neighbor for water by the drum), and $25.8 \%$ report no BWD access.

\section{Measures}

The survey measured water quantity, quality, and accessibility by asking a series of items about a typical dry season week and typical rainy season week for each water source used by the household. The survey was developed through a combination of literature review, a qualitative pilot study, and survey pilot testing followed by modification prior to fielding. Although self-report can be less reliable than direct observation for some measures (e.g., volume consumed), using a combination of 
Table 1 Household characteristics $(N=396)$

\begin{tabular}{lllll}
\hline Characteristic & Mean or \% & SD & Min & Max \\
\hline HH size (\#) & 4.4 & 2.1 & 1.0 & 13.0 \\
Monthly income $^{\text {a }}$ & & & & \\
$\quad$ Dry season () & 15,174 & 10,963 & 718 & 77,000 \\
$\quad$ Rainy season ( ) & 14,092 & 10,519 & 700 & 70,000 \\
Savings, any (\%) & 55.5 & & & \\
Homeownership (\%) & 55.4 & & & \\
Water storage & & & & \\
$\quad$ HH has tank(s) (\%) & 58.1 & & & \\
$\quad$ Tank storage capacity (L) & 1527.0 & 1711.4 & 0.0 & $12,000.0$ \\
$\quad$ HH has drum(s) (\%) & 73.2 & & & \\
$\quad$ Drum storage capacity (L) & 403.5 & 400.9 & 0.0 & $3,000.0$ \\
$\quad$ Total tank/drum capacity (L) & 1934.1 & 1640.2 & 0.0 & $12,800.0$ \\
Access to BWD connection (\%) & & & & \\
$\quad$ Private & 43.2 & & & \\
$\quad$ Shared/other way & 31.1 & & & \\
$\quad$ None & 25.8 & & & \\
\hline
\end{tabular}

$H H$ household, Philippine pesos ( 42.8 to $\$ 1$ ), $L$ liters, BWD Baguio Water District

${ }^{\text {a }} N=347(12.3 \%$ missing $)$

objective, perceptual, and experiential measures like the approach here can be desirable for understanding multiple dimensions of everyday household water security (Carolini 2012; Hadley and Wutich 2009).

Quantity was operationalized as (1) reported household consumption, scaled to liters per capita per day and totaled across all sources (LPCPD) (to wit, households were first asked to report household consumption by source; the research team then calculated total and per capita consumption for analysis); (2) perceived sufficiency of water overall (whether in a typical week the household always has enough, sometimes does not have enough, or often does not have enough water to meet its needs); and (3) experienced insufficiency of water (whether in a typical week there are times that the household does not have enough water for at least one specific need: drinking, cooking, bathing, washing dishes, laundry, household cleaning, or sanitation). Quality was operationalized as the respondent's perception of water cleanliness overall and for each specific need. For this, respondents chose a number on an 11-point phrase completion item (Hodge and Gillespie 2007) where $0=$ Not clean at all and $10=$ Completely clean. Accessibility was operationalized as (1) perceived ease of obtaining water overall (11-point phrase completion item; $0=$ Not easy at all, $10=$ Extremely easy); (2) water expenses, scaled to pesos per month (akin to water consumption, respondents first reported expenses by source, either weekly or monthly); and (3) affordability calculated for analysis as water expenses as a percentage of household income.

\section{Analyses}

Data were analyzed with descriptive statistics and bivariate analyses using SAS 9.3. The non-parametric Wilcoxon Signed-Rank test was used to analyze seasonal change in reported consumption, cleanliness overall and by specific need, perceived ease of obtaining water, and water expenses, due to non-normal mean differences in continuous variables. Due to paired data in categorical variables, McNemar's chisquare was used to analyze seasonal change in perceived sufficiency, experienced insufficiency, and affordability.

To explore if aggregate, multidimensional measures of water security would emerge from the data, principal component analyses (PCAs) were run by season, also with SAS 9.3. PCAs used an eigenvalue criterion of 1.0 , minimum factor loadings of 0.40 , and oblique rotation to allow correlation among components (Kolenikov and Angeles 2009; Vyas and Kumaranayake 2006). Each seasonal PCA included: reported consumption (log-transformed), perceived sufficiency, experienced insufficiency (separate items for drinking, cooking, bathing, washing dishes, laundry, household cleaning, and sanitation), perceived cleanliness (separate items for cooking, bathing, washing dishes, laundry, household cleaning, and overall), perceived ease, whether the household has ever borrowed water, whether the household has ever borrowed money to pay for water, whether the household has to choose between spending for water versus food, and whether the household uses particular water sources (BWD, delivery, spring, rainwater, recycled, any other source).

\section{Results}

\section{Household Water Sources}

A comparison of the percentage of households using each water source by season informs an initial picture of the household water situation in Pinget (Table 2), before specific water security measures are presented. Across both seasons, about $70 \%$ of Pinget households report using BWD water. While this may seem reasonably high or close to the common perception in Baguio City that about $80 \%$ of households have BWD access, only $43.2 \%$ of households, as noted above, report accessing BWD through their own piped connection. Others typically pay a landlord or relative for BWD water at a rate approximately four times higher than BWD's rate. Also, since it is common knowledge in the area that BWD water supply during the dry season is often low or unpredictable, many households supplement BWD with other sources, particularly private delivery truck water. In the rainy season, when BWD supply is stronger and rainwater abundant, many of these households no longer purchase delivery water. 
Table 2 Household water source(s) by season $(N=396)$

\begin{tabular}{lcc}
\hline Percentage of HHs using source & & \\
\hline Water source & Dry season & Rainy season \\
\hline BWD, own connection & 41.9 & 42.8 \\
BWD, shared/other way & 29.6 & 26.6 \\
Delivery truck & 34.3 & 23.2 \\
Purified (5-gal) & 92.4 & 92.7 \\
Spring & 8.3 & 2.9 \\
Rainwater & 46.5 & 81.2 \\
Recycled & 88.4 & 43.9 \\
Other (e.g., deep well) & 6.3 & 5.2 \\
\hline
\end{tabular}

$H H$ household, BWD Baguio Water District

For the rainy season, $N=383 ; 13$ cases $(3.28 \%)$ moved to Pinget after the most recent rainy season

Notably, rainwater is collected and used by some households in both seasons. Even in the dry season, almost half (46.5\%) of households report some rainwater usage, although substantially more $(88.4 \%)$ report using recycled water. During the rainy season, these percentages nearly reverse.

\section{Water Quantity}

Turning to this study's specific water security measures, reported amounts, perceptions, and experiences of water quantity vary widely among Pinget households in both seasons (Table 3). For the dry season, average reported consumption is 68.5 LPCPD. There is a wide range from under 10 to over 400 LPCPD, with about half of households (49.0\%) reporting consumption below the minimum recommended standard of 50 LPCPD (Gleick 1998). For the rainy season, a wide range in reported consumption is again observed: from less than 7 to almost 400 LPCPD, with a mean of 66.3. Of note, average reported consumption decreases from the dry season to the rainy season (an unexpected direction) by 2.2 LPCPD, a statistically significant change (Wilcoxon Signed-Rank= $-4208, p=.01$ ).

Findings for perceived sufficiency and experienced insufficiency of water, meanwhile, are in expected directions. For the dry season, $48.2 \%$ of households report always having enough water, $45.7 \%$ report sometimes not having enough, and $6.1 \%$ report often not having enough. For the rainy season, these percentages improve substantially to 90.6, 9.4, and $0.0 \%$, respectively. As expected, a lower percentage of households reports always having enough in the dry than rainy season (McNemar's $S=158.4, d f=1, p<.001$ ). For experienced insufficiency, about one-quarter of households $(26.0 \%)$ report at least one household need for which they did not have enough water during a typical dry season week. During the rainy season, only $3.9 \%$ of households report experiencing insufficient water for at least one household need, a statistically significant decrease from the dry season (McNemar's $S=83.0, d f=1, p<.001$ ).

\section{Water Quality}

For perceptions of water quality, average overall cleanliness ratings are 7.5 in the dry season and 6.9 in the rainy season (Table 3). Wilcoxon Signed-Rank tests find that mean ratings are higher in the dry season than the rainy season overall $(p<.001)$ and for each specific need except sanitation ( $p=.58$ for sanitation, $p=.04$ for drinking, $p<.001$ for the other needs).

\section{Water Accessibility}

Like water quantity, water accessibility varies widely among Pinget households as measured in this study (Table 3). Mean ratings for perceived ease are 6.9 in the dry season with a standard deviation of 2.2, and 8.6 in the rainy season with a smaller standard deviation of 1.7. The seasonal difference is statistically significant (Wilcoxon Signed-Rank $=-15,316.5$, $p<.001$ ). In both seasons, the full range of responses was given. For the dry season, $26.1 \%$ of households chose from 0 to $5,29.1 \%$ from 6 to 7 , and $44.8 \%$ from 8 to 10 . For the rainy season, these percentages were $7.6 \%, 10.8 \%$, and $81.6 \%$, respectively.

Monthly household water expenses average 787 (\$18.39) in the dry season and $638(\$ 14.91)$ in the rainy season, with wide ranges, high standard deviations, and a statistically significant decrease (Wilcoxon Signed-Rank $=10,937.5$, $p<.001)$. For affordability, about half of households $(51.0 \%)$ spend 0 to $5.0 \%$ of their income on water in the dry season, about one-third (32.1\%) spend 5.1 to $10.0 \%$, and almost $17 \%$ spend $10.1 \%$ or more of their income on water. In the rainy season, these numbers change somewhat to 56.0, 30.5 , and $13.5 \%$, respectively, in a statistically significant way (McNemar's $S=12.5, d f=3, p=.006$ ). Of note, the average household in this study spends about $5 \%$ of its income on water in either season, exceeding a United Nations recommendation that water expenses should be $3 \%$ or less of household income (UNICEF and World Health Organization 2012).

\section{Multidimensional Water Security}

Exploring if a multidimensional measure would emerge from study data, the dry season PCA yielded six component measures of water security. The first two components corresponded to reduced forms of the perceived cleanliness and experienced insufficiency items, respectively. Among the remaining components, the third emerged as a multidimensional measure of water security — designated as dry season 
Table 3 Seasonal change in dimensional measures of household water security

\begin{tabular}{|c|c|c|c|c|c|c|c|c|c|}
\hline \multirow[t]{2}{*}{ Measure } & \multicolumn{4}{|c|}{ Dry season $(N=396)$} & \multicolumn{4}{|c|}{ Rainy season $(N=383)^{\mathrm{a}}$} & \multirow{2}{*}{$\begin{array}{l}\Delta_{\text {Seaso }} \\
p\end{array}$} \\
\hline & Mean or $\%$ & SD & Min & Max & Mean or $\%$ & SD & Min & Max & \\
\hline \multicolumn{10}{|l|}{ Quantity } \\
\hline Reported consumption (LPCPD) ${ }^{\mathrm{b}}$ & 68.5 & 60.2 & 7.7 & 406.4 & 66.3 & 57.8 & 6.7 & 391.1 & .01 \\
\hline \multicolumn{10}{|l|}{ Perceived sufficiency $(\%)$} \\
\hline Always has enough & 48.2 & & & & 90.6 & & & & $<.001$ \\
\hline Sometimes does not have enough & 45.7 & & & & 9.4 & & & & \\
\hline Often does not have enough & 6.1 & & & & 0.0 & & & & \\
\hline \multicolumn{10}{|l|}{ Experienced insufficiency (\%) } \\
\hline At least one $\mathrm{HH}$ need & 26.0 & & & & 3.9 & & & & $<.001$ \\
\hline \multicolumn{10}{|l|}{ Quality } \\
\hline Overall cleanliness ( 0 to 10$)$ & 7.5 & 1.7 & 1.0 & 10.0 & 6.9 & 1.9 & 1.0 & 10.0 & $<.001$ \\
\hline Drinking & 8.9 & 1.3 & 3.0 & 10.0 & 8.8 & 1.4 & 1.0 & 10.0 & .04 \\
\hline Cooking & 7.7 & 1.6 & 1.0 & 10.0 & 7.2 & 1.8 & 1.0 & 10.0 & $<.001$ \\
\hline Bathing & 7.6 & 1.5 & 1.0 & 10.0 & 7.0 & 1.8 & 1.0 & 10.0 & $<.001$ \\
\hline Dishes & 7.6 & 1.5 & 1.0 & 10.0 & 7.1 & 1.8 & 1.0 & 10.0 & $<.001$ \\
\hline Laundry & 7.6 & 1.5 & 1.0 & 10.0 & 6.9 & 1.8 & 0.0 & 10.0 & $<.001$ \\
\hline Cleaning & 6.9 & 2.4 & 0.0 & 10.0 & 6.6 & 2.1 & 0.0 & 10.0 & $<.001$ \\
\hline Sanitation & 5.7 & 2.8 & 0.0 & 10.0 & 5.8 & 2.3 & 0.0 & 10.0 & .58 \\
\hline \multicolumn{10}{|l|}{ Accessibility } \\
\hline Perceived ease ( 0 to 10$)$ & 6.9 & 2.2 & 0.0 & 10.0 & 8.6 & 1.7 & 0.0 & 10.0 & $<.001$ \\
\hline Expenses $(/ \text { month })^{\mathrm{c}}$ & 787 & 757 & 0 & 11,397 & 638 & 680 & 0 & 11,397 & $<.001$ \\
\hline \multicolumn{10}{|l|}{ Affordability as $\%$ of $\mathrm{HH}$ income $(\%)^{\mathrm{d}}$} \\
\hline 0 to $5.0 \%$ & 51.0 & & & & 56.0 & & & & .006 \\
\hline 5.1 to $10.0 \%$ & 32.1 & & & & 30.5 & & & & \\
\hline $10.1 \%$ or more & 16.9 & & & & 13.5 & & & & \\
\hline
\end{tabular}

LPCPD liters per capita per day, HH household, Philippine pesos ( 42.8 to $\$ 1$ )

${ }^{a}$ Rainy season data are missing for households residing in Pinget only during the dry season at the time of data collection (i.e., residents of approximately six months or less)

${ }^{\mathrm{b}} N=384$ dry; $N=373$ rainy

${ }^{\mathrm{c}} N=386$ dry; $N=370$ rainy

${ }^{\mathrm{d}} N=337$ dry; $N=318$ rainy

hardship - with positive loadings from the following: whether the household has ever borrowed water (0.60), whether the household has ever borrowed money to pay for water $(0.58)$, whether the household has to choose between spending for water versus food $(0.55)$, and whether the household uses rainwater (0.66). Among the household quartile with the highest hardship score (least water security), $82.0 \%$ had borrowed water, $53.0 \%$ had borrowed money to pay for water, $43.0 \%$ had chosen between spending on water versus food, and $86.0 \%$ had used rainwater in the dry season.

The rainy season PCA yielded seven component measures of water security. The first two again corresponded to perceived cleanliness and experienced insufficiency. Among remaining components, a meaningful multidimensional measure of water security did not emerge.

\section{Discussion}

Taken together, results suggest that important heterogeneities of seasonal water security exist among households in this study. For water quantity, wide ranges and high standard deviations for reported consumption (acknowledging possible limitations due to measurement error - in Pinget, it is unlikely that a household subsists on less than 10 LPCPD) suggest wide inequalities in actual consumption between households, which may to some extent reflect differential access to water. For example, when subsets of the sample are examined, households that rely mainly on BWD water through their own piped connections report significantly higher average consumption in the dry season (90.0 LPCPD) than households that rely primarily on BWD water through shared/other connections (40.1 LPCPD) or delivery water (65.0 LPCPD) 
(Welch's $F=30.96 ; d f=2,301 ; p<.0001)$. Meanwhile, the statistically significant decline in average reported consumption from the dry to rainy season is an unexpected finding. There are at least three possible explanations. First, some households that use both BWD and delivery water in the dry season may have overestimated their consumption due to irregular delivery orders which supplement BWD. Second, some households may have provided a lower-bound estimate of rainwater use in the rainy season due to drums and tanks overflowing with rain. Third, household water needs during the rainy season may decrease due to less frequent bathing and laundry.

Interestingly, when findings for perceived sufficiency and experienced insufficiency of water are compared, a notable discrepancy emerges. In the dry season, a combined $51.8 \%$ of households report sometimes or often not having enough water for household needs in a typical week, but when asked about specific needs, only $26.0 \%$ report that there are times in a typical week when the household does not have enough. In the dry season, the percentage also declines from $9.4 \%$ (perceived insufficiency) to $3.9 \%$ (experienced insufficiency). One explanation for this may be that the household water managers who were survey respondents-recalling that they were primarily women who would be expected to fulfill domestic responsibilities-perceived themselves as always finding a way to find water for their household's needs in the dry season, and were thus less likely to report that the household actually did not have enough for a particular need.

Although water quantity and accessibility (discussed below) may be more problematic for the average Pinget household in the dry season, quality may be of somewhat greater concern in the rainy season. Although the perceived cleanliness measure used here does not measure the biologic or chemical quality of water, findings suggest that BWD water in particular-which would be classified as an improved source for those with their own BWD access and which is generally more abundant in the rainy than dry season-may be perceived by households as of inadequate quality. In Pinget, like Baguio City in general, few households consume BWD for drinking. At the same time, although most findings for water quality were statistically significant, these changes between seasons may not be very large in a practical sense. The largest declines for bathing and laundry likely reflect increased turbidity of BWD water and other sources in the rainy season. Meanwhile, relatively higher ratings for drinking in both seasons reflect that households typically choose a source trusted enough for consumption - in almost all cases, purified water sold in 5-gal jugs. Relatively lower ratings for sanitation reflect that many households domestically recycle water for this purpose (e.g., water from bathing or laundry).

Of note, findings for accessibility may shed light on the earlier unexpected finding for a seasonal decline in reported consumption of water. Here, seasonal changes for accessibility seem to reflect that hardship of water is perceived or felt more in the dry than rainy season. Households may use similar amounts of water in both seasons, or in some cases more water in the dry season, but the difficulty and expense of obtaining and managing that water in the dry season may feel more cumbersome to many households. In the dry season, BWD, spring, and rainwater are less abundant, and wait times for delivery trucks are often longer. These delays may create an uncertainty and related sense of stress about water and everyday living, as usual household work cannot be done due to lack of water. In the rainy season, by contrast, BWD water pressure and regularity improve, spring and rainwater are abundant, and delivery trucks have sufficient supply, likely alleviating the feeling for many that water is difficult to obtain.

Finally, the multidimensional dry season hardship measure that emerged from study PCAs is comprised of experiential measures related to borrowing, spending decisions, and using rainwater in the dry season. While these particular experiences may be context-specific - in the Philippines, for example, there are cultural norms of bayanihan (community building or cooperation) and panagkuwak (giving consideration) that may be relevant for understanding water and money borrowing - it may be productive to test multidimensional experience-based measures in other settings as well. If such measures are reproduced and found valid and reliable, they may facilitate more rapid and less costly methods of assessing household water security in different contexts, when such methods are called for.

\section{Limitations}

Limitations of this study should be carefully considered when interpreting and discussing results. This study used a cross-sectional design with self-report and recall of seasonal data due to resource constraints for collecting multiple data waves. A lack of standardized measures for the broader water security concept is another limitation. While this study's multidimensional measures were informed by prior research and pilot tested, further validation is necessary. Also, the survey-fielding period corresponded with an unexpected rainier-than-usual dry season, which may have improved household supplies of rainwater and other sources. Although households were asked to think about a typical dry season week or typical rainy season week when answering questions, they were not directed to think about a particular year. Finally, possible problems of overestimating delivery water for the dry season and underestimating rainwater in the rainy 
season, previously described, are also limitations to consider when interpreting results.

\section{Conclusions}

Using a multidimensional approach, this study provides new evidence on seasonal water security and household disparities in an urban community. The combined focus on seasonality and urban areas is innovative and productive. In global water development, attention is often given to urban-rural disparities and the need for further progress in rural areas (Carolini 2012). While rural water development is still critically important, urban areas can also have significant disparities among households, which neighborhood or community-level studies such as this can unmask. Similarly, seasonality is more often discussed in the rural than urban water literature. Yet, seasonality is of growing importance in many urban areas worldwide due to combined trends of population growth, urbanization, and changing climates such as longer dry seasons and wetter rainy seasons (Muller 2007; Schneider et al. 2007).

Overall, with the exception of reported consumption, the average household in this study reported lower water quantity and accessibility in the dry than rainy season. This is largely due to seasonal abundance of rainwater, which improves supply from BWD and private delivery companies, and which many households can collect and use at no cost if they have sufficient storage containers. Even in the rainy season, however, there are some households that experience much less water security than others and which should draw the attention of policymakers and social welfare practitioners; for example, $9.4 \%$ report sometimes not having enough water, and $13.5 \%$ spend over $10 \%$ of income on water each month. While local policymakers should increase efforts to reduce dry season disparities in household water security - for example, through social policies that facilitate more equitable access to BWD connections, assistance with purchasing storage containers such as tanks and drums, and some kind of water safety net for the least water secure households - some social policy attention should also be directed toward households that experience water difficulties in the rainy season, ensuring that these households are not overlooked during times of what may be generally perceived as abundant water supply.

At the same time, this study's unexpected finding for reported consumption - that the average is higher in the dry than rainy season - calls for further investigation. Although possible measurement errors may help explain this finding, it may also be that some households consume more water in the dry season, yet experience a greater sense or feeling of water hardship at the same time due to difficulties of obtaining water. In some ways, this discrepancy may support the call for more multidimensional approaches to water security measurement, highlighting the potential value of using a combination of objective and subjective (e.g., perceptual, experiential) measures to more fully understand water security at the household level and within a community.

For Baguio City in particular, this study provides the first known source of randomly sampled water security data for a city neighborhood. While local agencies sometimes conduct intensive door-to-door surveys on social and environmentrelated conditions, rigorous random sampling to generate generalizable knowledge has rarely been done. The identified water security disparities should garner further attention from municipal authorities, who may be perceived as less aware of neighborhood-level issues (Cleto 2011). Although it is possible that these disparities are worse in Pinget than other neighborhoods, prior research suggests that other areas of Baguio City may have complex and disparate water situations as well (Mason 2012; Muni and Peñalba 2011).

Such attention would be timely, as Baguio City is one of eight cities involved in the Asian Cities Adapt initiative, which is sponsored in part by ICLEI Local Governments for Sustainability and the Potsdam Institute for Climate Impact Research. Findings from this study may thus inform how water security concerns are incorporated into climate adaptation planning. Under drier scenarios, Baguio City's adaptation plan may want to consider how the least secure households will realize some basic right to water, particularly if free sources such as springs and rainwater become less abundant, or if increased competition over water sources leads to rate increases that do greatest harm to the lowest income households. Under wetter scenarios, local authorities may consider how quality of water may be adversely affected, and how rainwater can be better harvested, stored, and distributed to those households with less water security in the rainy season. Under both scenarios, this study highlights the need for social policy and action that ensures more equitable access to adequate amounts of clean, affordable, and obtainable water.

Moving forward, more rigorous documentation of local inequities is also needed, incorporating seasonal aspects of water security that are appropriate for local contexts. Motivated by professional ethics and values to identify, understand, and address disparities that unjustly affect vulnerable or marginalized groups, social welfare scholars have a unique opportunity to make important contributions to this emerging area. Indeed, unmasking these disparities - and doing so by season - should be an emerging priority for what Bradley and Bartram (2013) describe as the third phase of global water development, wherein improvements beyond basic access become the focus.

As organizations such as the United Nations and World Health Organization look beyond benchmarks like the Millennium Development Goals and toward universal access and coverage of water as a human right, more microscale analyses such as this study can inform where and how to 
target social policies that address water inequities at community and municipal levels. In turn and as Pawar (2013) notes, social welfare practitioners will then have increasingly important opportunities to advocate for and help implement such policies, using critical community engagement, organizing, and policy practice skills that are as relevant and applicable to addressing water security as they are to other social welfare concerns.

Acknowledgments This study was supported by the Center for Social Development, Chancellor's and Olin Fellowships, and Brown School International Dissertation Award at Washington University in St. Louis, and the Cordillera Studies Center at the University of the Philippines Baguio.

\section{References}

Asian Development Bank (2006). Sustainable water integrated management and governance for Baguio City. Manila, Philippines: Author

Baguio Water District (2011). 2011 annual report. Baguio City, Philippines: Author.

Bradley, D. J., \& Bartram, J. (2013). Domestic water and sanitation as water security: monitoring, concepts and strategy. Philosophical Transactions of the Royal Society A, 371, 20120420.

Carolini, G. Y. (2012). Framing water, sanitation, and hygiene needs among female-headed households in periurban Maputo, Mozambique. American Journal of Public Health, 102(2), 256-261.

Cheng, J. J., Schuster-Wallace, C. J., Watt, S., Newbold, B. K., \& Mente, A. (2012). An ecological quantification of the relationships between water, sanitation and infant, child, and maternal mortality. Environmental Health, 11, 4.

Cleto, M. L. C. (2011). Baguio's urban ecosystem: A scoping study. Report prepared for the Tebtebba Foundation: Indigenous People's International Centre for Policy Research and Education. Baguio City, Philippines: Tebtebba Foundation.

Dominelli, L. (2013). Environmental justice at the heart of social work practice: greening the profession. International Journal of Social Welfare, 22, 431-439.

Fehr, A., Sahin, M., \& Freeman, M. C. (2013). Sub-national inequities in Philippine water access associated with poverty and water potential. Journal of Water, Sanitation, and Hygiene for Development, 3, 638645.

Gleick, P. H. (1998). The human right to water. Water Policy, 1, 487-503.

Guardiola, J., \& García-Muñoz, T. (2011). Fulfilment of basic needs from a subjective point of view in rural Guatemala. International Journal of Social Welfare, 20, 393-403.

Hadley, C., \& Wutich, A. (2009). Experience-based measures of food and water security: biocultural approaches to grounded measures of insecurity. Human Organization, 68(4), 451-460.

Hamdan, S. M. (2009). A literature based study of stormwater harvesting as a new water resource. Water Science and Technology, 60(5), $1327-1339$.

Hodge, D. R., \& Gillespie, D. F. (2007). Phrase completion scales: a better measurement approach than Likert scales? Journal of Social Service Research, 33(4), 1-12.

Howard, G., \& Bartram, J. (2003). Domestic water quantity, service level, and health. Geneva: World Health Organization.

Jepson, W. (2014). Measuring 'no-win' waterscapes: experience-based scales and classification approaches to assess household water security in colonias on the US-Mexico border. Geoforum, 51, $107-120$.

Kemp, S. (2011). Recentring environment in social work practice: necessity, opportunity, challenge. British Journal of Social Work, 41(6), 1198-1210.

Kolenikov, S., \& Angeles, G. (2009). Socioeconomic status measurement with discrete proxy variables: is principal component analysis a reliable answer? Review of Income and Wealth, $55(1), 128-165$.

Mason, L. R. (2012). Gender and asset dimensions of seasonal water insecurity in urban Philippines. Weather, Climate, and Society, 4(1), 20-33.

McDonald, R. I., Green, P., Balk, D., Fekete, B. M., Revenga, C., Todd, M., \& Montgomery, M. (2011). Urban growth, climate change, and freshwater availability. Proceedings of the National Academies of Sciences USA, 108(15), 6312-6317.

Muller, M. (2007). Adapting to climate change: water management for urban resilience. Environment and Urbanization, 19(1), 99-113.

Muni, R. A., \& Peñalba, M. (2011). Final report on resource based conflicts in the time of climate change: The problem of water \& waste management in the BLISTT area. Baguio City, Philippines: Cordillera Studies Center, University of the Philippines Baguio.

Pajuelas, B. G. (2000). A study of rainfall variations in the Philippines. Science Diliman, 12(1), 1-28.

Pawar, S. (2013). Water insecurity: a case for social policy action by social workers. Australian Social Work, 66(2), 248-260.

Philippines Institute for Development Studies. (2009). Coping with climate variability and change. Development Research News, 28(5), 1-5.

Pickering, A. J., \& Davis, J. (2012). Freshwater availability and water fetching distance affect child health in sub-Saharan Africa. Environmental Science and Technology, 46(4), 23912397.

Romero, L. P. (2010). Water in Mexico City: what will climate change bring to its history of water-related hazards and vulnerabilities? Environment and Urbanization, 22(1), 157-178.

Rybski, D., Spies, M., \& Zhou, B. (2014). Summary of research on area-specific climate change scenarios for cities in the Philippines. Technical report prepared for Asian Cities Adapt. Potsdam, Germany: Potsdam Institute for Climate Impact Research.

Satterthwaite, D. (2003). The millennium development goals and urban poverty reduction: great expectations and nonsense statistics. Environment and Urbanization, 15(2), 181190.

Schmitz, C. L., Matyók, T., Sloan, L. M., \& James, C. (2012). The relationship between social work and environmental sustainability: implications for interdisciplinary practice. International Journal of Social Welfare, 21, 278-286.

Schneider, S. H., Semenov, S., Patwardhan, A., Burton, I., Magadza, C. H. D., Oppenheimer, M., Pittock, A. B., Rahman, A., Smith, J. B., Suarez, A., \& Yamin, F. (2007). Assessing key vulnerabilities and the risk from climate change. In M. L., Parry, O. F. Canziani, J. P. Palutikof, P. J. van der Linden, \& C. E. Hanson (Eds.), Climate change 2007: Impacts, adaptation and vulnerability. Contribution of working group II to the fourth assessment report of the Intergovernmental Panel on Climate Change (pp. 779-810). Cambridge, United Kingdom: Cambridge University Press.

Subbaraman, R., Shitole, S., Shitole, T., Sawant, K., O’Brien, J., Bloom, D. E., et al. (2013). The social ecology of water in a Mumbai slum: failures in water quality, quantity, and reliability. BMC Public Health, 13, 173.

UNICEF \& World Health Organization. (2012). Progress on drinking water and sanitation: 2012 update. New York: WHO/ 
UNICEF Joint Monitoring Programme for Water Supply and Sanitation.

United Nations Development Programme (2006). Human development report 2006: Beyond scarcity: Power, poverty, and the global water crisis. New York: Author.

United Nations Population Division (2010). World urbanization prospects: The 2009 revision: Highlights. New York, NY: Author.

Vairavamoorthy, K., Gorantiwar, S. D., \& Pathirana, A. (2008). Managing urban water supplies in developing countries - climate change and water scarcity scenarios. Physics and Chemistry of the Earth, 33(5), 330-339.
Vyas, S., \& Kumaranayake, L. (2006). Constructing socio-economic status indices: how to use principal components analysis. Health Policy and Planning, 21(6), 459-468.

Wutich, A., \& Ragsdale, K. (2008). Water insecurity and emotional distress: coping with supply, access, and seasonal variability of water in a Bolivian squatter settlement. Social Science and Medicine, 67(12), 2116-2125.

Yumul, G. P., Cruz, N. A., Servando, N. T., \& Dimalanta, C. B. (2011). Extreme weather events and related disasters in the Philippines: 2004-2008: a sign of what climate change will mean? Disasters, $35(2), 362-382$. 